\title{
ACESSIBILIDADE EDUCACIONAL, COMUNICACIONAL E SOCIAL EM TEMPOS DE PANDEMIA: DESAFIOS E PERSPECTIVAS
}

\author{
Edicléa Mascarenhas Fernandes ${ }^{\mathrm{i}}$ \\ Felipe Vieira Monteiro ${ }^{\text {ii }}$ \\ Aida Guerreiro de Oliveira ${ }^{\text {iii }}$
}

\begin{abstract}
Resumo: Devido à pandemia pelo Coronavírus (Covid-19), tornaram-se necessárias adequações, especialmente nos setores de trabalho e educação. Entretanto, pessoas que vivem em espaços periféricos subordinados aos grandes centros, além das pessoas com deficiência, percebem-se ainda mais invisibilizadas. Portanto, este artigo tem como objetivo abordar a importância dos recursos de tecnologia assistiva que promovem a autonomia e independência das pessoas com deficiência, especificamente no contexto educacional, formal ou informal. Recursos como audiodescrição, pranchas de comunicação, pictogramas, linguagem simples, bem como a Língua Brasileira de Sinais são oferecidos de forma insuficiente, embora tenhamos a legislação brasileira específica vigente. Fundamentamos este estudo na importância da luta pelo coletivo e na influência dos conselhos de direitos na vida da sociedade.
\end{abstract}

Palavras-chave: Pandemia; Educação; Pessoas com deficiência; Conselhos de direitos.

\section{EDUCATIONAL, COMMUNICATIONAL AND SOCIAL ACCESSIBILITY IN TIMES OF PANDEMIC: CHALLENGES AND PERSPECTIVES}

\begin{abstract}
Adaptations have become necessary as a result of the Coronavirus (Covid-19) pandemic, especially in the work and education sectors. However, people who live in peripheral spaces subordinated to large centers, in addition to people with disabilities, find themselves even more invisible. Therefore, this paper aims to address the importance of assistive technology resources, which promote the autonomy and independence of people with disabilities, specifically in the educational, formal or informal context. Resources such as audio description, communication boards, pictograms, simple language, as well as the Brazilian Sign Language are insufficiently offered, although we have the specific Brazilian legislation in force. This study is based on the importance of the struggle for the collective and the influence of rights councils on life in society.
\end{abstract}

Keywords: Pandemic; Education; Disabled people; Rights councils.

\section{Introdução}

A pandemia pelo Coronavírus (Covid-19), decretada pela Organização Mundial de Saúde em 2020 de forma súbita, marcou novas formas de relacionamentos e vivências sociais: restrição de contato social e de deslocamento, produzindo novas formas de relação com o trabalho e a educação. Neste sentido, irrompem os usos da tecnologia como forma de mediação 
e recolocação das formas de contato entre seres humanos. Diversos profissionais passam a atuar no seu próprio domicílio em espaços improvisados e a internet surge como a grande redentora de um "novo modo de organização humana". Professores organizam aulas on-line e as lives assumem na rede de computadores um espaço de conquista da verdade.

O artigo propõe uma discussão inicial acerca da comunicação em tempos de Covid, no que diz respeito aos aspectos das contradições de pontos de vista, à forma como a mídia apresenta e representa os atores deste processo e suas formas de lidar com o isolamento e às ressignificações da internet como espaço escolar e profissional. A seguir, delimitando o foco na pessoa com deficiência, discutem-se a acessibilidade e o uso das tecnologias em seus aspectos legais no âmbito internacional e nacional, pensando a acessibilidade como princípio inalienável para a cidadania e inclusão educacional e social.

Nesta discussão, enfatiza-se a importância dos movimentos sociais como espaços de formação e das ações da universidade nas brechas possíveis para articulação com Associações de Direitos, Conselhos e Secretarias de Educação, numa interlocução possível através das diversas mídias disponíveis (WhatsApp, e-mails, Facebook e links para encontros, como Google Meet), bem como as formas de encontro para aqueles grupos mais vulneráveis que sequer têm acesso à telefonia celular.

Numa perspectiva reflexiva acerca do universo informacional nestes meses de pandemia, o artigo que apresentamos propõe discussões sobre o acesso às informações e o uso das tecnologias, sobretudo em relação a grupos historicamente excluídos do acesso a estas.

\section{A informação em tempos de Covid: para quem?}

Os noticiários apresentam documentários sobre uma série de questões suscitadas por esse novo modo de relacionamento: Como as crianças estão reagindo trancafiadas em suas casas? De que forma pais estão organizando rotinas para acesso às aulas on-line? Quais as principais consequências emocionais e posturais do uso excessivo dos computadores? Quais os melhores ângulos para se produzir um bom vídeo a partir do celular?

Percebe-se um estado, por vezes de contradição, que oscila entre a negação maníaca e a dolorosa experiência de isolamento compulsório, as perdas e lutos e o risco real de contaminação. Neste sentido, a mídia apresenta números, curvas, tendências, escândalos de uso inadequado de verbas. Bourdieu et al. (1997) refletem acerca da mídia e do jornalismo: 
Os jornalistas, submetidos às exigências que as pressões ou as censuras de poderes internos e externos fazem pesar sobre eles, e sobretudo a concorrência, portanto a urgência, que jamais favoreceu a reflexão, propõem muitas vezes, sobre os problemas mais candentes, descrições e análises apressadas, e amiúde imprudentes; e o efeito que produzem, tanto no universo intelectual como no universo político, é ainda mais pernicioso, às vezes, porque estão em condição de se fazer valer mutuamente e de controlar a circulação dos discursos concorrentes, como os da ciência social (BOURDIEU et al., 1997, p. 733).

$\mathrm{Ou}$, por outro lado, deslocam o foco da argumentação que poderia assumir um caráter de discussão mais ampliada para o modelo hegemônico social meritocrático e do herói, em tempos de pandemia é o idoso de 104 anos, ex-combatente que venceu o vírus; ou a pessoa com deficiência com agravos de saúde que sobreviveu ao Covid, isolando assim a questão individual e os condicionantes sociais. Este caráter aniquilador da mídia, ao deslocar a discussão do panorama social geral para o individual, é também analisado por Gohn (2014):

No plano da sociedade, nos meios de comunicação, quando um canal de TV ou um jornal, por exemplo, apresentam projetos sociais, vemos um recorte que dá ênfase ao indivíduo isolado, como um herói que venceu na vida. O caráter educativo, do processo social implícito, fica diminuído à medida que, ao invés de contar processos, como um grupo que se articulou para implementar algo, relata-se a história de personagens individuais, caindo nessa banalização que a mídia faz hoje ao só focar os "pop stars" e suas banalidades, não se interessando pelos reais problemas do conjunto da população. A mídia podia trabalhar a questão da conscientização para a cidadania, mas não o faz (GOHN, 2014, p. 46).

Em contrapartida, um bombardeio de informações e orientações sanitárias nos meios de comunicação e nas redes sociais assinadas por epidemiologistas, sanitaristas de organismos internacionais e nacionais irrompem nas mídias, apresentando formas de prevenção em relação ao contágio pelo vírus, como uso correto de máscaras, associadas também a informações fakes (mentirosas). Sendo assim, seguem os usuários analisando e contrapondo informações advindas dos mais variados espaços para que possam organizar um mapa mental para o enfrentamento desta situação nova em seus espaços vivenciais.

Retomando às reportagens dos grandes noticiários que analisam o impacto do isolamento e do uso das redes sociais, pergunta-se: De que infância os meios de comunicação falam quando apresentam crianças envolvidas em suas aulas on-line? E as outras infâncias: As crianças que vivem em condições sub-humanas em espaços periféricos próximos a lixões sanitários, em casas de palafitas, ou as que moram em barracos com dez pessoas por cômodo, sem água e saneamento? Ou ainda quando apresentam orientações sobre contágio com fotos e imagens sem descrição? Ou comunicações de órgãos oficiais sem intérpretes de língua de 


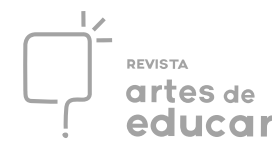

sinais? Ou termos e conceitos complexos que dificultam a popularização das informações científicas?

As soluções de orientação prescritas pela Organização Mundial de Saúde e pelos órgãos de saúde dos países falam para interlocutores que representam uma determinada parcela da população. Como afirma Araujo e Fernandes (2020) em estudo acerca do cuidado com pessoas com deficiência em tempos de Covid-19:

[...] quando se produzem materiais impressos e na mídia em orientação para higienização, são feitos a partir do ideário de corpos considerados normais, não se mencionam os corpos das pessoas com deficiência, suas órteses, próteses, cadeiras de rodas, enfim suas ajudas técnicas que são extensões corporais (ARAUJO; FERNANDES, 2020, p. 5472).

\section{Acessibilidade: um caminho de luta pela garantia de direitos}

O direito de acesso aos bens e serviços tem sido uma luta do movimento das pessoas com deficiência iniciado na década de 1960, junto a demais movimentos de luta pela igualdade de direitos e a outros movimentos de segmentos excluídos socialmente. Na década de 1970, consolidaram-se em diversos países leis e atos normativos que garantiam a entrada de crianças e jovens com deficiência nas escolas públicas locais, nascendo assim o movimento da integração e as modalidades de atendimento da Educação Especial.

No Brasil, embora tenhamos a história do atendimento a cegos e surdos desde o Brasil Império, foi também na década de 1970 que é criado o primeiro sistema normativo nacional da Educação Especial, o Centro Nacional de Educação Especial (CENESP). Sendo assim, estados e municípios iniciam a implantação de seus serviços de atendimento, com modalidades de salas de recursos, itinerância, classes e escolas especiais e, ainda previstas, mas não consolidadas na maior parte dos estados brasileiros, as classes hospitalares e os atendimentos pedagógicos domiciliares.

Os vinte anos que seguiram à implantação do CENESP revelaram questões inquietantes como, por exemplo, o fato dos serviços de Educação Especial não atenderem alunos com deficiência, indica o fracasso escolar como apontado em estudos como Paschoalick (1981), Yamamoto (1988), Schielmann (1989) analisados em Fernandes (1991).

Neste caminho, a tendência internacional, apontada nas Declarações de Jomtien (UNESCO, 1990), Salamanca (UNESCO, 1994) e Dakar (UNESCO, 2000), propunha a educação inclusiva para os direitos do acesso à educação de segmentos excluídos dos sistemas 
educacionais, bem como o destino do fracasso escolar e evasão destes grupos, dentre eles as pessoas com deficiência. Por influência destas Declarações e Convenções Internacionais, o Brasil passa a ser signatário e a incorporar ao seu sistema legal os princípios destas Convenções, assumindo em suas políticas, não somente no âmbito da acessibilidade à educação, mas também os demais bens e serviços.

Nos últimos vinte anos, tivemos uma série de legislações nacionais que garantem a acessibilidade ao segmento das pessoas com deficiência. Destacamos algumas destas legislações: o Decreto n. 5.296/2004 que estabeleceu os princípios da acessibilidade não somente no plano físico, mas também comunicacional e atitudinal; a Lei n. 10.436/2002 que instituiu oficialmente a Língua Brasileira de Sinais (Libras); e o Decreto n. 6.949/2009 que incorpora o texto legal da Convenção Internacional de Direitos da Pessoa com Deficiência de 2008.

O Decreto n. 7.612/2011 instituiu a Política Nacional de Direitos da Pessoa com Deficiência, o Plano Viver sem Limites, cuja finalidade era promover, por meio da integração e da articulação de políticas, programas e ações, o exercício pleno e equitativo dos direitos das pessoas com deficiência para garantir a participação em um sistema educacional inclusivo; e acesso à saúde, aos equipamentos de apoio, ao trabalho, à tecnologia, à inovação e aos programas de combate à pobreza, como benefício de prestação continuada, residências inclusivas. Essa política propunha quatro eixos: acesso à educação, atenção à saúde, inclusão social e acessibilidade. E destaca-se como auge desta luta a promulgação da Lei Brasileira de Inclusão (LBI) ou Estatuto da Pessoa com Deficiência (Lei n. 13.146/2015), pautada no Decreto n. 6.949/2009 e na Convenção Internacional dos Direitos da Pessoa com Deficiência, que se destina a assegurar e a promover, em condições de igualdade, o exercício dos direitos e das liberdades fundamentais da pessoa com deficiência, visando à sua inclusão social e cidadania.

O importante marco teórico desta lei foi deslocar o conceito de deficiência do âmbito pessoal, a partir de uma racionalidade médica, para o contexto social. Neste sentido, a deficiência passa a ser relativizada a partir do momento que barreiras sejam suprimidas. Portanto, os suportes são fundamentais, sejam eles físicos, tecnológicos ou humanos.

A LBI é uma lei nova que implica uma ruptura epistemológica com lógicas coloniais e normalizadoras, que propõem políticas de educação, saúde e urbanismo a partir de padrões de corpos, comunicação e cultura impostos por modelos considerados normais e universais. Não basta somente o texto da lei para que as rupturas aconteçam como de forma mágica, pois as 
concepções encontram-se arraigadas em modelos preconceituosos que normalizam a ausência de acessibilidade como algo da prática da benevolência ao invés de uma violação de direitos.

Em Epistemologias do Sul, Santos e Meneses (2009, p. 30-31) nos ajudam a compreender a necessidade dessa ruptura ao afirmarem que "a negação de uma parte da humanidade é sacrificial, na medida em que constitui a condição para a outra parte da humanidade se afirmar enquanto universal". Baseado numa perspectiva de ecologia de saberes e da não submissão a um modelo colonial, há a necessidade da percepção de um pluralismo epistemológico, não mais um monopólio epistêmico.

Porém esse monopólio sistêmico é vivenciado no dia a dia das pessoas com deficiência quando não têm acesso a transportes, rampas, guias e piso podo-táteis nas calçadas para se locomoverem com bengalas, sinais sonoros, informações em Libras e em código Braille. E ocorre nas escolas com a falta de intérpretes de Libras, de livros acessíveis, carteiras e materiais didáticos adaptados aos diferentes perfis anatômicos.

\section{As formas de acessibilidade em seus diferentes contextos}

Como vimos na seção anterior, as pessoas com deficiência, como todas as outras, têm o direito de acesso a informação, educação, saúde, lazer, transporte, entre outros, como é citado na legislação brasileira. Entretanto, nem sempre a sociedade está preparada para as especificidades de cada público. Tais necessidades são omitidas de maneira que muitos se sentem ainda mais segregados.

No que diz respeito à inclusão, é necessário entendermos de que maneira é possível promover a equidade de acesso para todos. Segundo o site do Ministério da Ciência, Tecnologia, Inovações e Comunicações do governo brasileiro (2020), a tecnologia assistiva compreende o desenvolvimento e pesquisa de instrumentos; e tem o intuito de ampliar a autonomia de pessoas com deficiência ou mobilidade reduzida em todas as suas atividades do dia a dia. Englobam-se produtos, metodologias, recursos, estratégias práticas e serviços com o objetivo de promover a qualidade de vida, independência e inclusão social.

Podemos citar alguns destes recursos de acessibilidade que devem estar disponíveis em todas as áreas supracitadas, a exemplo da audiodescrição, que é voltada prioritariamente para pessoas com deficiência visual, cegas e com baixa visão. Todavia o recurso pode beneficiar pessoas com deficiência intelectual, transtorno do espectro autista, síndrome de Down, dislexia, déficit de atenção, além de idosos e pessoas com baixo letramento. 
A audiodescrição é uma tradução do signo visual para o verbal, ampliando o entendimento do público. Descrições de ações, características físicas, expressões faciais, objetos, entre outros, estão no escopo do recurso, segundo Sá (2015). Aplica-se em programas de TV, sites da internet, redes sociais digitais, eventos pedagógicos como aulas, palestras, seminários, além do material de divulgação elaborado pelo setor da saúde, segundo Motta e Romeu Filho (2010).

As pessoas com deficiência visual podem contar ainda com auxílios no computador que facilitem o aumento das letras, lupas, telelupas e leitores de tela para possibilitar o acesso à internet. Neste sentido, é necessário que orientações impressas, emitidas por órgãos de saúde, sejam produzidas em fonte ampliada, com alto contraste, além do Braille. As mídias televisivas devem ter audiodescrição em toda a sua programação e os sites da internet com acessibilidade total, corroborando com o art. 67 da Lei Brasileira de Inclusão/Estatuto da Pessoa com Deficiência n. 13.146, de 06 de julho de 2015, caput e incisos I, II e III:

Art. 67. Os serviços de radiodifusão de sons e imagens devem permitir o uso dos seguintes recursos, entre outros:

I - subtitulação por meio de legenda oculta;

II - janela com intérprete da Libras;

III - audiodescrição (BRASIL, 2015).

A Libras é uma língua visual necessária ao processo de comunicação das pessoas surdas e, desde 24 de abril de 2002, foi reconhecida como a segunda língua oficial brasileira pela Lei n. 10.436. É constituída por sinais e gestos com estrutura própria e de eficiência comunicativa como as línguas orais. Esta língua necessita ser incorporada em meios digitais de informação, nos ambientes educacionais e no atendimento da área de saúde.

As pessoas que não oralizam e não possuem a escrita funcional, tais como com deficiência intelectual, transtorno do espectro autista, entre outros, podem contar com a comunicação alternativa. Segundo Massaro (2012), tal comunicação colabora para o processo de aquisição e desenvolvimento da linguagem e para o desenvolvimento da competência comunicativa, a exemplo dos pictogramas, que são imagens que transmitem informações sem o apoio de textos. Para Dranka (2012), são representações gráficas de objetos, conceitos abstratos e narrativas que têm por finalidade uma comunicação simples com eficiência e de maneira direta sem a necessidade do apoio de textos. Essa interação ocorre através das pranchas de comunicação que são elaboradas de forma personalizada para atender às especificidades do usuário. 
Exposto este panorama da ausência de acesso à comunicação e acessibilidade para as pessoas com deficiência, podemos imaginar, ao longo do ciclo de vida dessas pessoas, situações inquietantes e que violam direitos como, por exemplo: uma criança de três anos que não sustenta o tronco e não há uma carteira adaptada em sua sala de aula da pré-escola; um graduando cego que não utiliza a biblioteca porque não há computador com leitor de tela; uma mulher surda em trabalho de parto e não há profissional que se comunique em Libras; uma peça de teatro sem audiodescrição; um folder sobre prevenção de diabetes sem linguagem simples em seu texto e nenhuma imagem ilustrativa, inacessível a pessoas com limitações cognitivas, ou ainda sem versão em Braille; escadas na entrada da promotoria; ruas sem piso podotátil.

Este é o mundo, ou pelo menos o retrato da situação brasileira em fevereiro de 2020 , quando as autoridades sanitárias mundiais e os órgãos públicos oficializaram a pandemia e os primeiros casos no país. Neste contexto, refletimos sobre o universo das pessoas com deficiência em suas singularidades e restrições já anteriores a este cenário.

\section{O triângulo da pandemia e o sistema de conselhos: saúde, educação e acessibilidade}

O momento crítico da pandemia, instalada também no país, gera determinada insegurança, abalando as estruturas em âmbito geral. Perguntas afloram, tais como: De que forma os alunos darão continuidade ao ano letivo? As atividades on-line surgem como panaceia para esta questão. E, como analisamos anteriormente, a que alunos estamos nos referindo? Todos com acesso à internet?

Uma rede de informações passa a ser orientada: formas de lavar as mãos, uso adequado do sabonete nos dedos, álcool gel, máscaras descartáveis, máscaras produzidas, estratégias de prevenção ao contágio. Neste universo de contradições, parte da população se movimenta por ordens: fique em casa, mude os hábitos, alimente-se saudavelmente, mantenha uma distância de 1 metro, espirre no braço, não saia de casa, conecte-se para se manter vinculado ao mundo.

Diante deste imprevisível mundo novo nem todos ficaram dentro dos espaços possíveis das ordens de sobrevivência, e mais uma vez o mundo é socialmente dividido entre aqueles que podem se manter em isolamento e prevenção e aquela parcela sem acesso, seja pelas necessidades financeiras concretas ou pelas limitações físicas, sensoriais, cognitivas, condições de doenças raras que em contato com as diversas barreiras as impedem de se adequar ao "mundo novo", como é o caso das pessoas com deficiência. 
Diante deste quadro exposto, pode-se perceber a invisibilidade das pessoas com deficiência: professores produzem aulas dentro das condições possíveis de seus lares sem acessibilidade a muitos de seus alunos, que por vezes sequer possuem algum tipo de acesso à internet e, se tiverem a necessidade de uma audiodescrição ou Libras, ficarão fora do contexto. Por outro lado, prefeitos e governadores fazem previsões de retorno às aulas se a redução da pandemia ocorrer, mas os alunos com deficiência não fazem parte destas previsões com adequações necessárias.

Não podemos descartar as minorias que representam uma grande e densa parte da população brasileira, que muitas vezes se alojam ou habitam áreas consideradas periferias urbanas. Os espaços considerados periféricos geralmente são caracterizados como desqualificados, marginalizados e subordinados aos grandes centros. Segundo Lima (2015), as periferias se mantêm como minorias subordinadas ao centro que, por sua vez, permanece consolidando sua supremacia.

Por outro lado, não se pretende, neste artigo, conceber as periferias urbanas como espaços meramente passivos, mas como espaços de crescimento e desenvolvimento sociocultural, inclusive de pessoas que apresentam deficiências diversas, o que não lhes impede de atuarem no mercado de trabalho, produzindo em iguais condições de quaisquer pessoas, independente dos espaços periféricos onde habitam. A trajetória de pessoas com deficiência em âmbito social, educacional, tecnológico e laboral não é neutra por estar envolvida nas contradições de luta, resistência e resiliência no dia a dia, e a luta pela acessibilidade é uma constante.

A acessibilidade tem caráter decisório para a inclusão social das pessoas com deficiência, pois “[...] se constitui como uma quebra de paradigmas, de uma perspectiva meramente adaptacionista da pessoa com deficiência para uma perspectiva de direito e funcionalidade" (FERNANDES; ORRICO, 2012, p. 99). A tentativa de minorias sair da invisibilidade impulsionou a criação de conselhos de direitos com equivalência na paridade dos membros, constituindo representações de diversos grupos que se apresentam como minorias, estimulando a vez e a voz destas, as quais também são peças imprescindíveis para o avanço do quebra-cabeça que são as políticas públicas neste país.

As pessoas com deficiência e condições raras diversas precisam de um mundo apropriado às suas necessidades, tanto em relação aos espaços físicos como aos comunicacionais, inclusive no aspecto das atitudes dos indivíduos no que diz respeito a este grupo social. Percebe-se ao longo do texto que no mundo pré-pandemia esses direitos ainda não 
estavam consolidados. E estas imposições sanitárias e incertezas ou expuseram de vez a total vulnerabilidade em que vivem ou, pior ainda, maior invisibilidade deste segmento.

Os movimentos sociais e os conselhos de direitos são fundamentais na busca por essas garantias. Embora, desde a década de 1960, diversas associações passem a se organizar nessa luta para direitos de acesso a educação, saúde, trabalho, locomoção e lazer; ainda não se constitui como realidade. Observemos o que afirma Santos (2020) em relação às pessoas com deficiência:

[...] têm sido vítimas de outra forma de dominação, além do capitalismo, do colonialismo e do patriarcado: o capacitismo. Trata-se da forma como a sociedade os discrimina, não thes reconhecendo as suas necessidades especiais, não thes facilitando acesso à mobilidade e às condições que lhes permitiriam desfrutar da sociedade como qualquer outra pessoa. De algum modo, as limitações que a sociedade lhes impõe fazem com que se sintam a viver em quarentena permanente (SANTOS, 2020, p. 20).

Como viverão a nova quarentena, sobretudo quando dependem de alguém que a viole para lhes prestar alguma ajuda? Como já há muito se habituaram a viver em condições de algum confinamento, sentir-se-ão agora mais livres que os "não deficientes" ou mais iguais a eles? Verão tristemente na nova quarentena alguma justiça social?

Aos Conselhos, cabe o registro das denúncias recebidas, bem como as devidas orientações e providências. As deliberações também fazem parte das ações destes, porém um dos pontos fundamentais de associações de direitos e do sistema de conselhos é o de serem espaços de formação. Gohn (2014) esclarece que movimentos sociais são espaços não formais, sobretudo em espaços periféricos:

A educação não formal é aquela que se aprende "no mundo da vida", via os processos de compartilhamento de experiências, principalmente em espaços e ações coletivos cotidianas. Nossa concepção de educação não formal articulase ao campo da educação cidadã - a qual no contexto escolar pressupõe a democratização da gestão e do acesso à escola, assim como a democratização do conhecimento. Na educação não formal, essa educação volta-se para a formação de cidadãos(as) livres, emancipados, portadores de um leque diversificado de direitos, assim como de deveres para com o(s) outro(s).

[...] a educação não formal é uma ferramenta importante no processo de formação e construção da cidadania das pessoas, em qualquer nível social ou de escolaridade, destacando, entretanto, sua relevância no campo da juventude. Pelo fato de ser menos estruturada e mais flexível, consegue atingir a atenção e o imaginário dos jovens. Quando é acionada em processos sociais desenvolvidos em comunidades carentes socioeconomicamente, ela possibilita processos de inclusão social via o resgate da riqueza cultural daquelas pessoas, expressa na diversidade de práticas, valores e experiências anteriores (GOHN, 2014, p. 40-42). 
O momento atípico que estamos vivenciando devido à pandemia que se instalou em nosso país nos leva a indagar sobre as transformações, as quais estão sendo priorizadas em nossas vidas, em diversas esferas: familiar, profissional, acadêmica, funcional e outras. $\mathrm{O}$ impacto gerado atingiu vários âmbitos: educação, saúde, economia, esporte e lazer. Os órgãos governamentais, sem planejamento prévio, tiveram urgência em criar possibilidades alternativas, ou até mesmo paliativas, com a finalidade de dar continuidade a suas programações do ano em curso.

De acordo com Gohn (2006), a transmissão de informação e formação política e sociocultural é uma meta na educação não formal, pois prepara os cidadãos, educa o ser humano para a civilidade, em oposição à barbárie, ao egoísmo e ao individualismo. E os sistemas de conselho precisaram reinventar suas práticas de reuniões por meio de canais de internet para garantirem seus vínculos e espaços de luta. Simson, Gohn e Fernandes (2007) explicitam onde as práticas de educação não formal ocorrem:

As práticas da educação não-formal se desenvolvem geralmente fora dos muros da escola - nas organizações sociais, nos movimentos e programas de formação sobre direitos humanos, cidadania, práticas identitárias e lutas contra a desigualdade e a exclusão social. Essas práticas estão no centro das atividades das ONGs e dos programas de inclusão, especialmente no campo das artes, educação e cultura (SIMSON; GOHN; FERNANDES, 2007, p. 13).

Queiroz e Fernandes (2020), ao analisarem os resultados do IV Encontro dos Conselhos de Direitos da Pessoa com Deficiência, realizado em dezembro de 2018, identificaram a representação de 23 municípios do Estado do Rio de Janeiro, dentre eles identificou-se o expressivo quantitativo de presença de 6 conselhos da baixada fluminense, área periférica do Estado que é composta por 9 municípios, o que representa uma grande capacidade de organização do movimento. $\mathrm{O}$ foco deste encontro foi identificar a transversalidade das políticas públicas em relação à garantia de direitos das pessoas com deficiência entre outros pontos.

O encontro realizado ao longo do dia identificou, por meio de apresentações das lideranças e questionário com perguntas, a existência de equipamentos previstos no Decreto n. 7.612/2011 que instituiu a Política Nacional de Direitos da Pessoa com Deficiência, o Plano Viver sem Limites.

Analisando os resultados apresentados pelas autoras, percebe-se a necessidade de consolidação de políticas públicas para o segmento: dos 23 municípios presentes 15 não oferecem classes hospitalares, 14 não oferecem atendimento pedagógico domiciliar, 6 não dispõem da sala de recursos nas escolas públicas, 12 não possuem centros de apoio educacional 
especializado e 15 não oferecem educação precoce para alunos com necessidades especiais de 0 a 5 anos; apenas 1 município oferece residência inclusiva, 11 ofertam abrigos e somente 2 com Centro de Convivência para Jovens e Adultos. Em relação à acessibilidade urbana que se refere à estrutura física, como calçadas, praças e parques acessíveis, terminais de ônibus, estações de trem e metrô, terminal de barcas com acessibilidade, espaços de lazer e ônibus adaptado, mais da metade do quantitativo dos municípios presentes não oferece essas condições básicas para locomoção das pessoas com deficiência.

Além da representação de lideranças de Conselhos do Estado do Rio de Janeiro, o referido encontro reuniu importantes associações emergentes, como Associação Lótus que reúne famílias de crianças acometidas pela Síndrome Congênita pelo Zika Vírus; e o Comitê Estadual para Doenças Raras, como Fibrose Cística, Acondroplasia, Osteogênese Imperfeita, Síndrome de Prader-Willi e Esclerose Múltipla, que reúne representantes de diversas associações.

Em relação ao processo de formação que encontros de conselhos propiciam, é uma riqueza de trocas de experiências horizontais. Os encontros de conselhos nacionais, estaduais e regionais atualizam as diversas formas de participação, empoderando as pessoas com deficiência e suas famílias. Os enfrentamentos das barreiras no dia a dia já não são poucos e, nesse momento de pandemia, irrompem todas as faltas das políticas, mas também podem surgir as brechas para resiliências por meio das trocas e parcerias.

Gohn (2014) enfatiza a ideia de que a participação tende a aumentar à medida que o indivíduo envolve-se no processo de socialização, quanto mais as pessoas participam, mais tendem a continuar neste caminho, por romperem com a tradição de distanciamento de decisões. Somente atuando o indivíduo se habilita à participação, no sentido pleno da palavra, que inclui o fato de tomar e ter parte no contexto em que estão inseridos. A autora (GOHN, 1997) destaca ainda:

Movimentos sociais são ações sociopolíticas construídas por atores sociais pertencentes a diferentes classes e camadas sociais articuladas segundo uma identidade de interesses comuns amalgamada pela força do princípio da solidariedade. Esta solidariedade é construída a partir de uma base cultural referencial de valores compartilhados pelo grupo em espaços coletivos não institucionalizados tendo como suporte entidades e organizações da sociedade civil com agendas de atuação construídas ao redor de demandas socioeconômicas ou político-culturais que abrangem certas problemáticas conflitivas na sociedade (GOHN, 1997, p. 11).

A pandemia tem suscitado mudanças dos modos de produção pautados num modelo do capital selvagem. Os bens de consumo básico, marcas famosas, empresas de turismo, tudo passa 
a ser relativizado. Algumas cidades em lockdown, distanciamento social e alto índice de desemprego têm exposto de maneira dramática os nichos da exclusão social de segmentos pobres da população sem acesso a saneamento, água potável e moradias dignas. Expôs a fragilidade da organização dos sistemas de saúde na atenção básica e complexidade, da educação e da mobilidade urbana.

Neste sentido, pergunta-se: Haverá possíveis brechas e rupturas epistemológicas que possamos localizar no momento social advindo da pandemia?

\section{Movimentos sociais de pessoas com deficiência, pesquisa, extensão universitária e gestão pública: possíveis alternativas para o enfrentamento da pandemia}

A pandemia interrompeu a docência e o convívio nas salas de aula dos espaços universitários, porém a universidade é feita de um tripé: ensino, pesquisa e extensão, sendo que estas duas últimas não foram interrompidas. Universidades públicas uniram-se em projetos para produção de máscaras e protetores faciais para profissionais de saúde, pesquisas para mapeamento e sequenciamento do vírus, estudos de medicamentos mais eficazes, bioestatística para identificar e analisar curvas epidemiológicas.

As lives, um dos recursos comumente utilizados nos meios de comunicação oficiais e nas redes pessoais durante os meses de pandemia, tornaram-se um recurso amplamente utilizado pelas universidades para que debates ao vivo fossem organizados sob forma de pequenos simpósios, seja para orientação, como também para discussões de temas nas mais diversas redes sociais, como Facebook, Instagram e sites. A seguir, destacamos algumas produções do Núcleo de Educação Especial e Inclusiva (NEEI) da Universidade do Estado do Rio de Janeiro (UERJ), por meio de atividade extensionista que se pretende vincular as produções acadêmicas da universidade à diversidade humana nos aspectos sociais, linguísticos e culturais.

O Núcleo de Educação Especial e Inclusiva (NEEI/ UERJ) visa desenvolver atividades de ensino, pesquisa e extensão acerca da temática da Educação Especial na Perspectiva da Educação Inclusiva para pessoas com deficiência, transtornos globais do desenvolvimento, altas habilidades e superdotação. Congrega projetos de pesquisa, extensão, entre outras atividades relacionadas à temática.

O núcleo conta com acervo de monografias, teses e dissertações na área de Educação Especial e Inclusiva da Graduação e Pós-Graduação da UERJ e materiais fornecidos por outras 
graduações e programas de pós-graduação do Estado do Rio de Janeiro e do país; bem como publicações textuais, legislação internacional, nacional e vídeos de instituições da área. Outra importante fonte de consulta é o Banco de Dados de Adaptações Curriculares, que conta com aproximadamente 350 adaptações confeccionadas por alunos da disciplina "Prática Pedagógica em Educação Inclusiva", dos cursos de Licenciaturas da UERJ. Esses materiais servem de apoio didático para o processo de ensino e aprendizagem de alunos com deficiência, transtornos globais do desenvolvimento, altas habilidades e superdotação.

O NEEI conta também com computadores com leitores de tela, bookreader para escaneamento de textos, regletes, punções e sorobã para oficinas de tecnologia. No espaço virtual, os interessados podem buscar as produções científicas no site (www.neeiuerj.org.br). Os pesquisadores graduandos e pós-graduandos estão vinculados ao Diretório de Grupos de Pesquisa do CNPQ: Produção de Materiais Didáticos Acessíveis em Contextos Formais e Informais de Educação.

O grupo vem desenvolvendo de março a junho de 2020 pesquisa e extensão com o objetivo de contribuir não somente na perspectiva dos temas científicos, mas também no processo de acessibilidade de lives destinadas à orientação de profissionais e pessoas com deficiência. Outro objetivo é contribuir para o empoderamento de associações e conselhos de direitos em seus espaços de atuação neste momento de isolamento, com ênfase nos espaços da periferia do Estado do Rio de Janeiro.

\section{* Vídeo de orientação do Comitê Estadual de Doenças Raras}

O vídeo apresenta audiodescrição da imagem orientada pelo consultor do grupo de pesquisa e janela em Libras produzida e editada por outro membro do grupo. $\mathrm{O}$ vídeo é apresentado pela Coordenadora Estadual de Doenças Raras, que também é presidente da Associação Nacional de Osteogênese Imperfeita (ANOI). Ela aborda o conceito de doenças raras, apresenta as instituições que integram o Comitê, bem como os desafios dos pacientes e das famílias e a importância deste Comitê vinculado à Secretaria Estadual de Direitos Humanos (Disponível em: https://youtu.be/PWkBhr3sxIg).

\section{* Vídeo de orientação da Associação Lótus}

O vídeo apresenta audiodescrição da imagem orientada pelo consultor do grupo de pesquisa e janela em Libras produzida e editada pelo mesmo grupo. $\mathrm{O}$ vídeo é apresentado por um membro da diretoria da Associação Lótus para familiares de crianças acometidas pela Síndrome 
Congênita pelo Zika Vírus. No vídeo, discutem-se as causas e os agravos à saúde das crianças, sobretudo no comprometimento das vias aéreas superiores e função pulmonar, e orienta sobre os cuidados a serem tomados para evitar o contágio pelo Covid neste grupo de risco (Disponível em: https://youtu.be/mfcOb9D4BhM).

\section{* Vídeo sobre a Pessoa com Deficiência e o Coronavírus}

O vídeo apresenta audiodescrição da imagem orientada pelo consultor do grupo de pesquisa e janela em Libras produzida e editada pelo mesmo grupo. O vídeo apresenta uma discussão acerca da pessoa com deficiência (Disponível em:

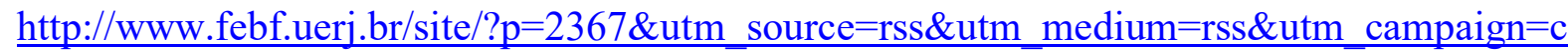
oronavirus-e-a-pessoa-com-deficiencia).

* Live de orientação para a equipe de profissionais de educação da Secretaria de Educação de Resende

Essa live em parceria com a Coordenação de Educação Especial do município de Resende apresentou discussão teórica e proposta de intervenções práticas e lúdicas para bebês e crianças com alterações no desenvolvimento. O objetivo era um diálogo com professores da educação infantil para que pudessem estabelecer, por meio das redes sociais, o contato com famílias de crianças com alterações do desenvolvimento que, no momento da pandemia, se encontram em isolamento domiciliar (Disponível em: https://youtu.be/w2m7NnjhOLM).

\section{* Live em parceria com a Secretaria de Educação de Nova Iguaçu sobre a educação} especial e inclusiva em tempos de pandemia

O vídeo apresenta debate entre a Coordenadoria de Educação Especial e o grupo de pesquisa com ênfase no processo educacional pré-pandemia e pós-pandemia de alunos com condições raras, e nas modalidades de atendimento da educação especial necessárias a este grupo, tais como itinerância e atendimento educacional em ambiente hospitalar e domiciliar (Disponível em: https://www.facebook.com/semednovaiguacu.rj/videos/593613821260204/).

\section{* Live sobre família, deficiência e tempos atuais}

O vídeo foi realizado em parceria com o Instituto Federal do Rio de Janeiro, a Universidade do Estado do Rio de Janeiro, a Universidade Federal do Rio de Janeiro e a Universidade Federal 
Fluminense. Consiste em um painel com especialistas, contando com acessibilidade em tradução para Libras (Disponível em: https://youtu.be/9-rfmrHTR1E).

\section{Rap Juntos contra o Coronavírus}

O rap foi organizado como uma campanha publicitária do Conselho Municipal de Direitos da Pessoa com Deficiência do Município de São João de Meriti. A letra é de composição de pessoa com deficiência visual, a edição, audiolegendagem inicial e versão em Libras realizadas pelos membros do conselho e apoio dos pesquisadores do NEEI/UERJ. A acessibilidade às imagens do vídeo, a sequência das imagens, bem como a versão simultânea em Libras oportunizam informação sobre prevenção de forma acessível e representa um trabalho colaborativo entre Conselho de direitos, universidade e artistas (Disponível em: https://drive.google.com/file/d/1niWESINJF--

I3I_RWbOA1fZFEVOvtk8y/view?usp=sharing).

\section{* Live sobre equidade comunicacional em tempos de pandemia}

Organizada pelo Programa de Pós-Graduação em Educação, Comunicação e Cultura da Faculdade de Educação da Baixada Fluminense, apresenta a discussão acerca da acessibilidade debatida por docente e dois discentes com deficiência visual, sendo um consultor em audiodescrição e outro presidente do Conselho Municipal de Direitos da Pessoa com Deficiência de São João de Meriti, um dos municípios que integra a região da baixada fluminense. A live conta com elementos de audiodescrição e tradução em Libras (Disponível em: https://www.facebook.com/watch/live/?v=282002513174883\&ref=watch permalink).

\section{Considerações finais}

A sociedade vem enfrentando um grande desafio ao atravessar a pandemia pelo Coronavírus (Covid-19) decretada pela Organização Mundial de Saúde. Com isso, as interações foram afetadas de forma repentina, fazendo com que novas relações de trabalho e de educação tivessem medidas emergenciais para adequação. Nesta direção, a internet vem como grande aliada para profissionais, os quais tiveram que se adequar em suas casas desenvolvendo trabalhos remotos. Da mesma forma que professores passaram a desenvolver conteúdos agora disponibilizados por meio de plataformas digitais.

Tendo em vista as adequações no contexto educacional, formal ou informal, torna-se necessária a disponibilização de conteúdos didáticos acessíveis a todos, devido à realidade dos 
estudantes, especificamente os que vivem em espaços periféricos, que são subordinados aos grandes centros, em condições sub-humanas. Muitas vezes estes estudantes não têm acesso às condições sanitárias básicas e, em algumas ocasiões, a presença da deficiência ainda se superpõe às questões sociais.

Apesar da existência de leis, garantindo os direitos das pessoas com deficiência, e dos programas propostos nos últimos anos, que culminaram com a promulgação da LBI (Lei n. 13.146/2015), os recursos de tecnologia assistiva são oferecidos de forma insuficiente. Tais recursos promovem a autonomia e independência deste público, especificamente os que contribuem para a equidade comunicacional, como a audiodescrição, a Libras, as pranchas de comunicação, os pictogramas e a linguagem simples. Dentro desta realidade, que invisibiliza esta parte da população, entendemos que a criação dos conselhos de direitos das pessoas com deficiência estimulou, nas últimas décadas, a voz e a vez das minorias, fomentando as políticas públicas no Brasil.

Finalmente concluímos que, se por um lado a pandemia trouxe lutos, dores, incertezas e denúncia exacerbada da ausência de acessibilidade em todos os níveis de segmento das pessoas com deficiência, por outro lado demonstrou a resiliência dos movimentos sociais, das associações, conselhos de direitos e pesquisadores que de forma colaborativa, a partir do uso de recursos das redes sociais, vêm fomentando debates, orientações e, sobretudo, demonstrando que é possível uma comunicação inclusiva, a popularização da ciência aos grupos da periferia, na contramão do que a mídia e os órgãos públicos propiciam.

\section{Referências}

ARAUJO, L. A. S. de; FERNANDES, E. M. O cuidado com pessoas com deficiência em tempos do COVID-19: considerações acerca do tema. Brazilian Journal of health Review, Curitiba, v. 3, n. 3, p. 5469-5480, may/jun. 2020. Disponível em: http://www.brazilianjournals.com/index.php/BJHR/article/view/10849/9074. Acesso em: 15 jun. 2020.

BOURDIEU, P. et al. A miséria do mundo. 17. ed. Petrópolis: Vozes, 1997.

BRASIL. Decreto n. 5.296, de 02 de dezembro de 2004. Disponível em: http://www.planalto.gov.br/ccivil 03/ ato2004-2006/2004/decreto/d5296.htm. Acesso em: 10 maio 2020.

BRASIL. Decreto $n$. 6.949, de 25 de agosto de 2009. Disponível em: http://www.planalto.gov.br/ccivil 03/ ato2007-2010/2009/decreto/d6949.htm. Acesso em: 10 maio 2020. 
BRASIL. Decreto n. 7.612, de 17 de novembro de 2011. Disponível em: http://www.planalto.gov.br/ccivil 03/ Ato2011-2014/2011/Decreto/D7612.htm. Acesso em: 15 maio 2020.

BRASIL. Lei n. 10.436, de 24 de abril de 2002. Disponível em: http://www.planalto.gov.br/ccivil 03/leis/2002/110436.htm. Acesso em: 25 maio 2020.

BRASIL. Lei n. 13.146, de 06 de julho de 2015. Disponível em: http://www.planalto.gov.br/ccivil_03/ ato2015-2018/2015/lei/113146.htm. Acesso em: 9 maio 2020 .

DRANKA, L. K. Pictogramas: teoria, desenvolvimento e aplicação: The Noun Project: análise e adaptação ao português. Relatório de Iniciação Científica e Integração Acadêmica, Universidade Federal do Paraná, 2012. Disponível em: http://www.ciclovida.ufpr.br/wpcontent/uploads/2013/03/Relat\%C3\%B3rio-Lucas-K.-Dranka-Pictogramas-TeoriaDesenvolvimento-e-Aplica\%C3\%A7\%C3\%A3o.pdf. Acesso em: 29 set. 2020.

FERNANDES, E. M. A implantação do modelo pedagógico construtivista na Educação Especial do sistema público de Duque de Caxias: mudanças na prática pedagógica e institucional. Rio de Janeiro: UERJ, 1991. Dissertação (Mestrado em Educação) - Programa de Pós-Graduação em Educação, Universidade Estadual do Rio de Janeiro, Rio de Janeiro, 1991.

FERNANDES, E. M.; ORRICO, H. F. Acessibilidade e inclusão social. Rio de Janeiro: Deescubra, 2012.

GOHN, M. da G. Educação não formal, aprendizagens e saberes em processos participativos. Investigar em Educação, n. 1, 2014. Disponível em:

http://pages.ie.uminho.pt/inved/index.php/ie/article/view/4/4. Acesso em: 4 jun. 2020.

GOHN, M. da G.. Educação não-formal na pedagogia social. Congresso Internacional de Pedagogia Social, mar./2006. Disponível em:

http://www.proceedings.scielo.br/scielo.php?pid=MSC0000000092006000100034\&script=sci arttext. Acesso em: 3 jun. 2020.

GOHN, M. da G.. Movimentos, ONGs e lutas sociais no Brasil nos anos 90. In: Os sem-terra, ONGs e cidadania: a sociedade civil brasileira na era da globalização. São Paulo, Cortez, 1997.

LIMA, M. C. As teorias do desenvolvimento: a propósito dos conceitos de centro e periferia. Século XXI: Revista de Relações Internacionais - ESPM/Sul, [S.1.], v. 6, n. 1, p. 13-24, ago. 2015. ISSN 2236-871X. Disponível em: http://seculoxxi.espm.br/index.php/xxi/article/view/105. Acesso em: 20 maio 2020.

MASSARO, M. Música por meio de sistemas de comunicação alternativa: inserção do aluno com deficiência na atividade pedagógica. Orientadora: Débora Deliberato. Marília: UNESP, 2012. 113 f. Dissertação (Mestrado em Educação), Universidade Estadual Paulista, Faculdade de Filosofia e Ciências, Marília, 2012. Disponível em:

https://repositorio.unesp.br/bitstream/handle/11449/91189/massaro m me mar.pdf?sequence $=1 \&$ isAllowed=y. Acesso em: 29 set. 2020. 


\section{MINISTÉRIO DA CIÊNCIA, TECNOLOGIA, INOVAÇÕES E COMUNICAÇÕES.}

Tecnologia assistiva. Disponível em:

https://www.mctic.gov.br/mctic/opencms/ciencia/tecnologia assistiva/ assistiva/Tecnologia

Assistiva.html. Acesso em: 25 maio 2020.

MOTTA, L. M. V. M.; ROMEU FILHO, P. (Orgs.). Audiodescrição: transformando imagens em palavras. São Paulo: Secretaria de Estado dos Direitos da Pessoa com Deficiência, 2010.

QUEIROZ, K. G. de; FERNANDES, E. M. IV Encontro dos Conselhos de Direitos da Pessoa com Deficiência no Estado do Rio de Janeiro. In: Tópicos em Ciências Sociais. 1. ed., v. 4. Belo Horizonte: Poisson, 2020. p. 94-98.

SÁ, E. D. A consultoria na prática da audiodescrição: a perspectiva dos consultores com deficiência visual. UFJF, 2015. Trabalho de Conclusão de Curso (Curso de especialização em audiodescrição) - Faculdade de Educação Física e Desportos, Universidade Federal de Juiz de Fora, Juiz de Fora, 2015.

SANTOS, B. de S. A cruel pedagogia do vírus. Coimbra: Almedina, 2020.

SANTOS, B. de S.; MENESES, M. P. (Org.). Epistemologias do Sul. São Paulo: Cortez, 2009. $532 \mathrm{p}$.

SIMSON, O. R. de M. von; GOHN, M. da G.; FERNANDES, R. S. (Orgs.). Não-fronteiras: universos da educação não-formal. São Paulo: Itaú Cultural, 2007. 96 p. Disponível em: http://d3nv1jy4u7zmsc.cloudfront.net/wp-content/uploads/2012/02/000323.pdf. Acesso em: 27 nov. 2019.

UNESCO. Declaração de Salamanca. 1994. Disponível em: http://portal.mec.gov.br/seesp/arquivos/pdf/salamanca.pdf. Acesso em: 23 maio 2020.

UNESCO. Declaração mundial sobre educação para todos e plano de ação para satisfazer as necessidades básicas de aprendizagem. Jomtien, Tailândia: UNESCO, 1990.

UNESCO. Educação para todos: o compromisso de Dakar. Dakar, Senegal: UNESCO, 2000.

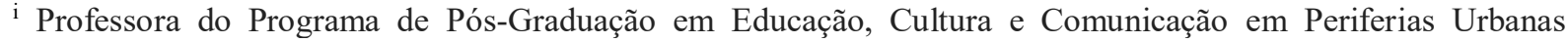
FEBF/UERJ e do Programa de Pós-Graduação em Ciências, Tecnologia e Inclusão/UFF. Rio de Janeiro, Brasil. E-mail: professoraediclea.uerj@gmail.com ORCID: http://orcid.org/0000-0003-3998-2016

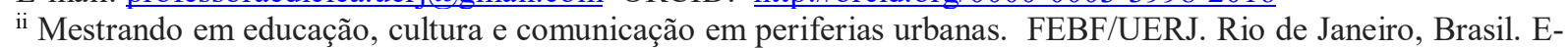
mail: consultorfelipemonteiro@gmail.com ORCID: https://orcid.org/0000-0001-8814-9245

iii Mestranda em educação, cultura e comunicação em periferias urbanas. FEBF/UERJ. Rio de Janeiro, Brasil. Email: aidaguerreiroeduc@gmail.com ORCID: https://orcid.org/0000-0002-9846-7666
} 